OPEN

SUBJECT AREAS:

ENVIRONMENTAL

MICROBIOLOGY

ARCHAEA BIOLOGY

Received

1 July 2013

Accepted

18 October 2013

Published

5 November 2013

Correspondence and requests for materials should be addressed to

M.W.F. (matthew.

fields@biofilm.

montana.edu)

* Current address: Department of Biology, Portland State

University, Portland, OR, USA

\section{Taxis Toward Hydrogen Gas by Methanococcus maripaludis}

\author{
Kristen A. Brileya ${ }^{1,2,4 *}$, James M. Connolly ${ }^{1,3}$, Carey Downey ${ }^{1,2}$, Robin Gerlach ${ }^{1,3}$ \& Matthew W. Fields ${ }^{1,2,4}$
}

${ }^{1}$ Center for Biofilm Engineering, Montana State University, Bozeman, MT, USA, ${ }^{2}$ Department of Microbiology, Montana State University, Bozeman, MT, USA, ${ }^{3}$ Department of Chemical and Biological Engineering, Montana State University, Bozeman, MT, USA, ${ }^{4}$ ENIGMA (http://enigma.lbl.gov).

Knowledge of taxis (directed swimming) in the Archaea is currently expanding through identification of novel receptors, effectors, and proteins involved in signal transduction to the flagellar motor. Although the ability for biological cells to sense and swim toward hydrogen gas has been hypothesized for many years, this capacity has yet to be observed and demonstrated. Here we show that the average swimming velocity increases in the direction of a source of hydrogen gas for the methanogen, Methanococcus maripaludis using a capillary assay with anoxic gas-phase control and time-lapse microscopy. The results indicate that a methanogen couples motility to hydrogen concentration sensing and is the first direct observation of hydrogenotaxis in any domain of life. Hydrogenotaxis represents a strategy that would impart a competitive advantage to motile microorganisms that compete for hydrogen gas and would impact the $\mathrm{C}, \mathrm{S}$ and $\mathrm{N}$ cycles.

$\mathrm{H}$ ydrogen gas $\left(\mathrm{H}_{2}\right)$ is a crucial substrate for methanogens as well as a common source of energy for other organisms in both anaerobic and aerobic environments, including acetogens, sulfate- and sulfur-reducers, and hydrogen-oxidizers ${ }^{1-4}$. Biological methane $\left(\mathrm{CH}_{4}\right)$ production from $\mathrm{H}_{2}$ and carbon dioxide $\left(\mathrm{CO}_{2}\right)$ contributes to greenhouse gas emissions and is possibly one of the oldest microbial metabolisms ${ }^{5,6}$. Understanding the ecological strategies of methanogens is not only important for our knowledge of early earth processes and present-day anaerobic environments, but also for determining potential roles in human health conditions (e.g., colon cancer and periodontal disease), where positive correlations have been made with incidence of disease and occurrence of methanogens ${ }^{7,8}$. Methanococcus maripaludis is an anaerobic archaeum that can use $\mathrm{H}_{2}$ or formate as electron donor to reduce $\mathrm{CO}_{2}$ to $\mathrm{CH}_{4}$ and is considered a model mesophilic methanogen. Recently, the swimming behavior of $M$. maripaludis was described ${ }^{9}$, but chemotactic responses have not been shown. Chemotaxis has been demonstrated for Archaea, including methanogens ${ }^{10,11}$, but taxis to hydrogen has not been shown for any domain of life. The chemotaxis signal transduction system in Archaea is similar to the well-studied system in Bacteria; however, the flagellar switch is different and none of the archaeal flagellar proteins have homologs to bacterial flagellar proteins ${ }^{12-15}$.

Chemotaxis has been the subject of many mathematical models and the majority have concentrated on reproducing the population-level observation of migrating bands of high cell concentration in swarm plates and capillary experiments ${ }^{16}$. Pioneering work in modeling chemotaxis behavior by Keller and Segel in 1971 has been the basis of the most common mathematical models ${ }^{17}$. In one dimension, with $\mathrm{x}$ being the spatial variable, the Keller-Segel model can be described as a flux, J, such that

$$
J=-\mu \frac{\partial b}{\partial x}+\chi(s) b \frac{\partial s}{\partial x}
$$

where $\mu$ is the cell diffusion coefficient that takes random, non-directed, movement of cells into account. b is the microbial population density, $s$ is the attractant concentration and $\chi(s)$ is the non-constant chemotactic coefficient. The population flux, J, can be differentiated to yield the more common form

$$
\frac{\partial b}{\partial t}=\frac{-\partial J}{\partial x}=\frac{-\partial}{\partial x}\left[-\mu \frac{\partial b}{\partial x}+\chi(s) b \frac{\partial s}{\partial x}\right]
$$

and the average cell swimming velocity, $\mathrm{v}$, is calculated by dividing the flux by the population density, or $\mathrm{v}=\mathrm{J} / \mathrm{b}$. Lapidus and Schiller ${ }^{18}$ proposed a form of $\chi(\mathrm{s})$ such that 


$$
\chi(s)=\chi \frac{k_{d}}{\left(k_{d}+s\right)^{2}}
$$

where $\chi$ is the constant chemotactic coefficient and $k_{d}$ is the receptorligand binding dissociation constant. The Lapidus-Schiller $\chi(s)$ term, and variations thereof, have been used widely to describe chemotaxis in bacteria ${ }^{19}$. Most work on archaeal chemotaxis has been performed with Halobacterium salinarum; however, attempts to mathematically describe population flux in archaea have not been published. In addition, $\chi$ and $\mathrm{k}_{\mathrm{d}}$ have not been determined for any archaea ${ }^{12,20-22}$.

The goal of the present study was to subject $M$. maripaludis cells to a $\mathrm{H}_{2}$ concentration gradient and compare swimming behavior to model predictions. Attractant $\left(\mathrm{H}_{2}\right)$ transport was modeled by Fickian diffusion and consumption by the population was modeled in the Michaelis-Menten form such that

$$
\frac{\partial s}{\partial t}=D \frac{\partial^{2} s}{\partial x^{2}}-\frac{r_{\max } b s}{\left(k_{m}+s\right)}
$$

where $\mathrm{D}$ is the diffusion coefficient for $\mathrm{H}_{2}, \mathrm{r}_{\max }$ is the maximum consumption rate, and $\mathrm{k}_{\mathrm{m}}$ is the half-saturation constant.

A modified capillary assay was used in which cells were loaded into a gas-tight anaerobic capillary under an anoxic atmosphere, and a valve allowed controlled exposure to a $\mathrm{H}_{2}$ source (see Supplementary Fig. S1 and S2 online). In previous experiments, capillaries that contained a dissolved chemoattractant were immerged into a cell suspension and cells entered the capillary in the presence of a chemoattractant over a known incubation time. The population increase in the capillary relative to a control was then quantified through cell enumeration ${ }^{23}$. For this study, a novel method was developed to directly observe microscopic swimming behavior of anaerobic cells inside a capillary during exposure to a gas. M. maripaludis cells were tracked for direction and velocity changes upon exposure to $\mathrm{H}_{2}$ or an Argon (Ar) control to quantify the average population-wide response. Cell movement was measured using time-lapse confocal laser scanning microscopy (CLSM) in the center of the capillary $(0.5 \mathrm{~cm}$ from the gas phase; as in Supplementary Fig. S1 online). A reaction-diffusion model predicted that within 10-15 minutes $\mathrm{H}_{2}$ concentrations would reach the threshold of $2.5-23 \mu \mathrm{M}$, at which hydrogenotrophic methanogens have been shown to use $\mathrm{H}_{2}$ in pure culture studies ${ }^{24-27}$ (Figure 1).

\section{Results}

When M. maripaludis cells were exposed to $\mathrm{H}_{2}$, the average swimming velocity exhibited significant bias toward $\mathrm{H}_{2}$ within ten minutes (Figure 2A). Biased random walk was not observed when cells were exposed to an $\mathrm{Ar}$ gradient (Figure 2B), nor was swimming velocity affected normal to the $\mathrm{H}_{2}$ or Ar gradients (Figures $2 \mathrm{C}$ and D). A strong chemotactic response was observed when cells were first starved of $\mathrm{H}_{2}$ for 4-5 hours, while cultures that had not been starved did not show an increase in biased swimming (see Supplementary Fig. S3 online). Similar results were observed in Rhodobacter sphaeroides and Sinorhizobium meliloti when well-fed cells exhibited weaker chemotactic responses than starved cells toward attractants such as organic acids and sugars. It was suggested that this was because chemosensory pathways in these organisms were dependent on metabolic state and/or transport ${ }^{28}$, as could be the case for $\mathrm{H}_{2}$ sensing in M. maripaludis.

The starvation period $(4-5 \mathrm{~h})$ that was required to induce a tractable response to $\mathrm{H}_{2}$ did not cause loss of motility, as observed during starvation of $H$. salinarum ${ }^{20}$. The average swimming speed of starved M. maripaludis cells was $2.1 \pm 0.05 \mu \mathrm{m} \mathrm{s}^{-1}$ before exposure to $\mathrm{H}_{2}$ (Figure 3A) and increased to $3.1 \pm 0.02 \mu \mathrm{m} \mathrm{s}^{-1}$ after exposure; equal to non-starved cells. Maximum swimming speed averages (calculated by averaging the single maximum speed from each time point) were highly variable between time points, and the average maximum
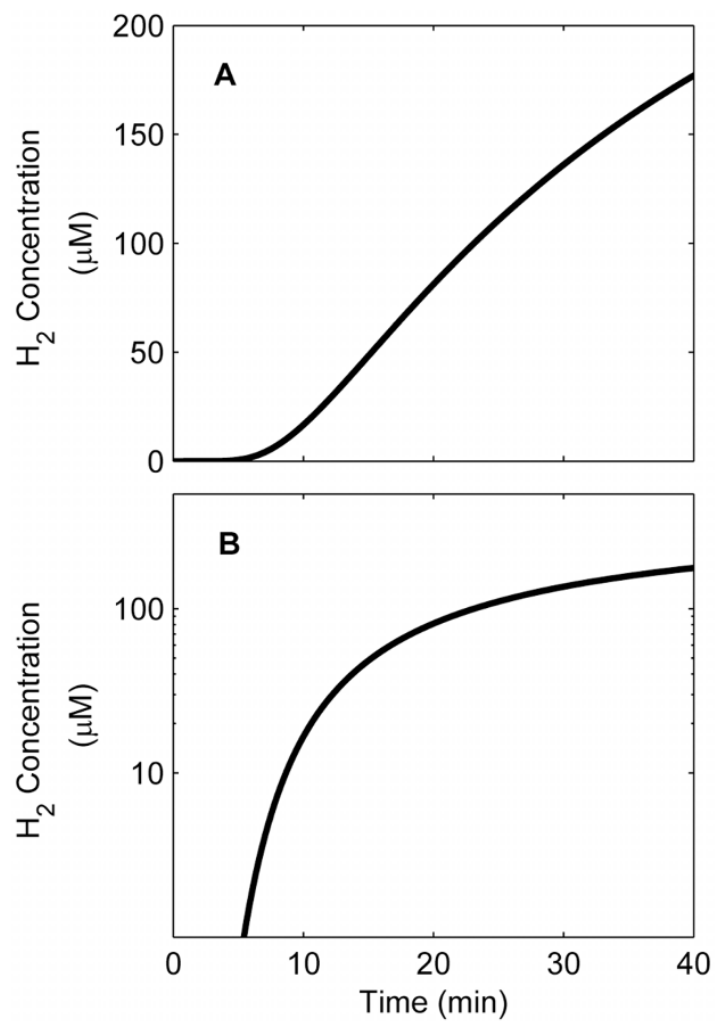

Figure $1 \mid$ The predicted hydrogen concentration over time at the observation point $0.5 \mathrm{~cm}$ from the gas phase over the course of the experiment shown with (A) linear axes and (B) log-linear axes. The 2.5$23 \mu \mathrm{M}$ threshold, at which hydrogenotrophic methanogens have been shown to use $\mathrm{H}_{2}$ in pure culture studies ${ }^{24-27}$, is reached at approximately 10 minutes.

was higher for non-starved cells $\left(9.3 \mu \mathrm{m} \mathrm{s}^{-1}\right.$ versus $8.5 \mu \mathrm{m} \mathrm{s}^{-1}$ for starved cells $+\mathrm{H}_{2}$ ) and lowest for starved cells before $\mathrm{H}_{2}$ exposure $\left(7.0 \mu \mathrm{m} \mathrm{s}^{-1}\right)$ (Figure 3B). The highest maximum observed speed was $91 \mu \mathrm{m} \mathrm{s}^{-1}$ for $\mathrm{H}_{2}$ starved cells after exposure to $\mathrm{H}_{2}$ (Figure 3B inner boxes), approximately twice the previously observed maximum speed of $45 \mu \mathrm{m} \mathrm{s}^{-1}$ for M. maripaludis ${ }^{9}$.

A Keller-Segel model was applied with boundary conditions specific to our study in an effort to quantify the observed chemotactic response to $\mathrm{H}_{2}$ in context with other known chemotactic responses. Currently, K-S model parameter values do not exist for any organism in Archaea or for any other gas besides $\mathrm{O}_{2}$; therefore, a broad range of $\mathrm{k}_{\mathrm{d}}$ values were used in the model. Three unknowns, namely ligandreceptor dissociation constant $\left(\mathrm{k}_{\mathrm{d}}\right)$, chemotactic coefficient $(\chi)$, and random cell diffusion coefficient $(\mu)$, were independently fitted by varying one unknown across the range of published literature values, while keeping the other two variables constant at the average literature values (see Supplementary Table S1 online). The best fit for average swimming velocity was obtained with a $k_{d}$ value of $0.70 \mathrm{mM}$, with 0.30 and $2.30 \mathrm{mM}$ corresponding to the $95 \%$ confidence interval of the data, while $\chi$ and $\mu$ were kept at average published values (Figure $4 \mathrm{~A}$ ). This range for $\mathrm{k}_{\mathrm{d}}$ is similar to that observed for Escherichia coli AW405 to $\alpha$-methyl aspartate ${ }^{29}$. It is; however, quite different from values reported for Bacillus subtilis receptor affinity to $\mathrm{O}_{2}(0.0015$ and $0.075 \mathrm{mM}$ for the high and low affinity of the receptor, respectively), which is the only previously reported $\mathrm{k}_{\mathrm{d}}$ for a gas ${ }^{30}$.

The model could also be fitted to the velocity curve by varying $\chi$ and keeping $\mathrm{k}_{\mathrm{d}}$ and $\mu$ constant at average literature values (Figure 4B). The average $\chi$ of $9.3 \times 10^{-3} \mathrm{~cm}^{2} \mathrm{~s}^{-1}$ used to fit the experimental results is higher than the literature range $7.20 \times 10^{-5}$ to $1.24 \times 10^{-3} \mathrm{~cm}^{2} \mathrm{~s}^{-1}$ (see Supplementary Table S1 online). The 

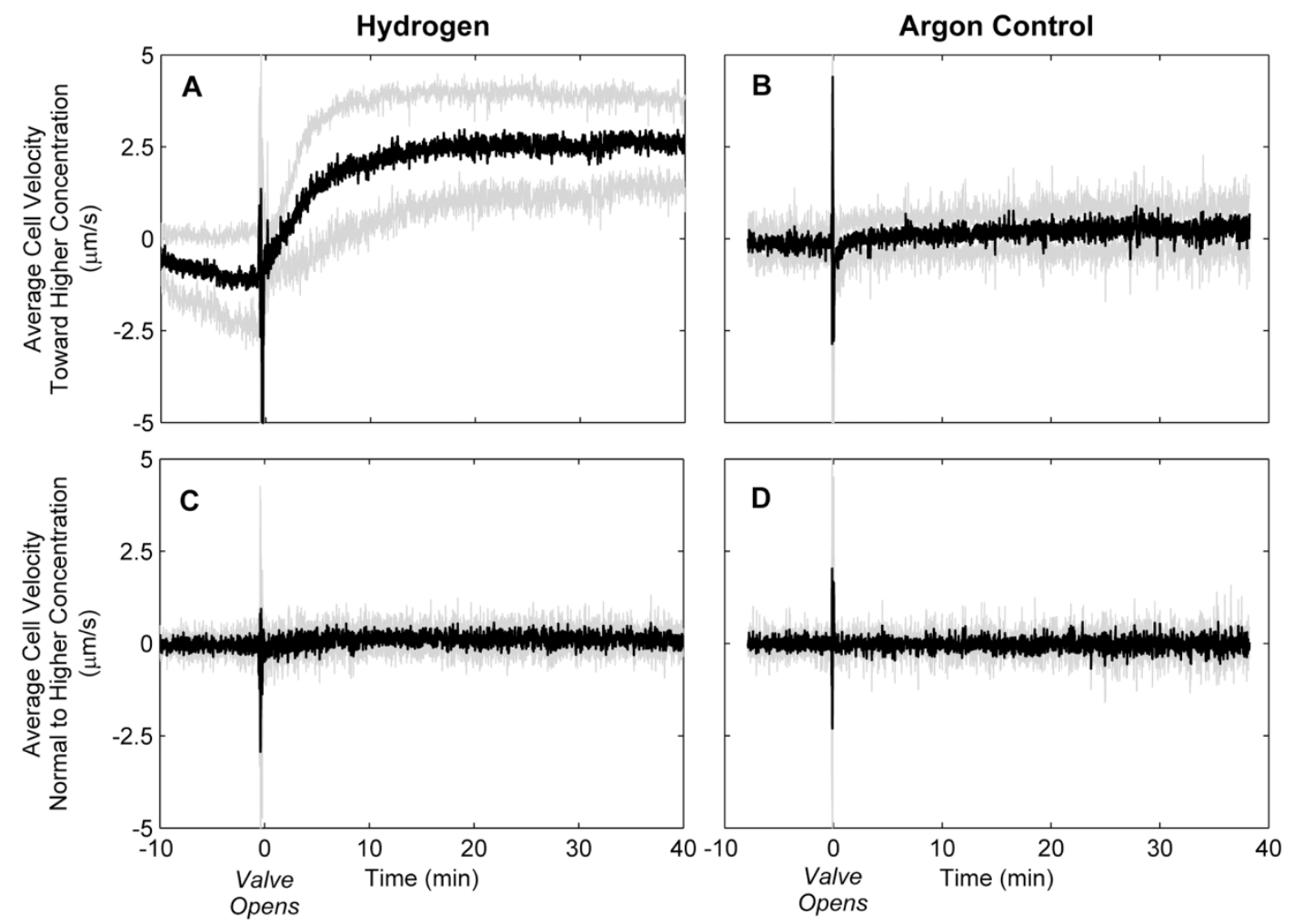

Figure $2 \mid$ Average cell velocity (black) with $95 \%$ confidence intervals (gray) before and after opening valve to gas phase for (A) $\mathrm{H}_{2}$ and (B) Ar control. Positive $y$-axis values indicate movement toward the gas phase, negative $y$-axis values indicate movement away from the gas phase. Average cell velocity (C) and (D) normal to concentration gradient ( $\mathrm{n}=5$ for $\mathrm{H}_{2}$ and $\mathrm{n}=3$ for $\mathrm{Ar}$ ).

experimental results were best fitted to the model that assumed the average published value for $\chi$, and then by varying $\mathrm{k}_{\mathrm{d}}$ (Figure $4 \mathrm{~A}$ ). The model could not be fitted to the experimental data by varying $\mu$ according to published values (Figure $4 \mathrm{C}$, note the difference in $\mathrm{y}$ axis scale); however, changing $\mu$ allowed for a change in shape of the velocity curve.

The response time predicted by the model does not fit the rapid response observed in the experiment and this is likely due to an inaccurate prediction of mass transport inside the capillary (for both $\mathrm{H}_{2}$ and cells). Both random cell diffusion $(\mu)$ and the diffusion of hydrogen would require correction from predicted values if mass transport was inaccurately represented. First, considering $\mu$ independently, it is likely that response time would be faster for cells with a larger $\mu$ (Figure $4 \mathrm{C}$ ). This is based on the proportionality of $\mu$ to swimming speed and run time, and inverse proportionality to one minus the cosine of the turn angle $\theta^{31}$. Although not measured directly here, $M$. maripaludis has been shown to have relatively long runs and small changes in direction or turn angles. Turn angles between 20 and $45^{\circ}$ would result in the largest value of $\mu$ for a given swimming speed and run time, so it is reasonable to assume $\mu$ would be higher for this type of swimming. The observed rapid response can be explained by an inaccurate prediction of $\mathrm{H}_{2}$ mass flux into the liquid domain. If $\mathrm{H}_{2}$ were to reach the observation point faster than predicted by the model, then one would predict a proportionally faster response. This was an entirely static system on a visually observable scale but it is possible that unpredictable micro-scale convective forces increased $\mathrm{H}_{2}$ mass transport. The collective, directed motion of swimming cells may have induced convective flow inside the capillary. Previous work estimates that a force of $0.5 \mathrm{pN}$ is exerted by a cell swimming at $25 \mu \mathrm{m} \mathrm{s}^{-1}$. While
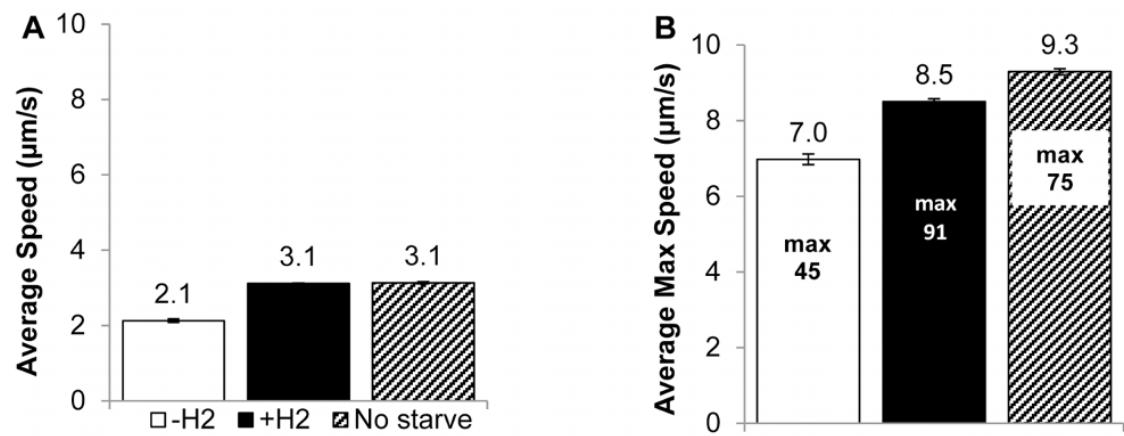

Figure 3 Swimming speed of $M$. maripaludis cells when starved for 5 hours before $\mathrm{H}_{2}$ exposure $\left(-\mathrm{H}_{2}\right.$ and $\left.n=4,725\right)$, after $\mathrm{H}_{2}$ exposure $\left(+\mathrm{H}_{2}\right.$ and $n=$ 20,189), and when not starved (No starve, $n=45,001$ ). Values represent the mean and error bars represent $95 \%$ confidence intervals. (A) Average swimming speed. The difference between $-\mathrm{H}_{2}$ and both $+\mathrm{H}_{2}$ and no starvation is significant $(\mathrm{p}<0.05)$. (B) Average maximum swimming speeds are represented by bars, and absolute maximum values inside each bar represent the highest observed speed over all time points for the condition. Differences between all conditions are significant $(\mathrm{p}<0.05)$ and $\mathrm{p}$ values were calculated with two-tailed $\mathrm{t}$-tests. 

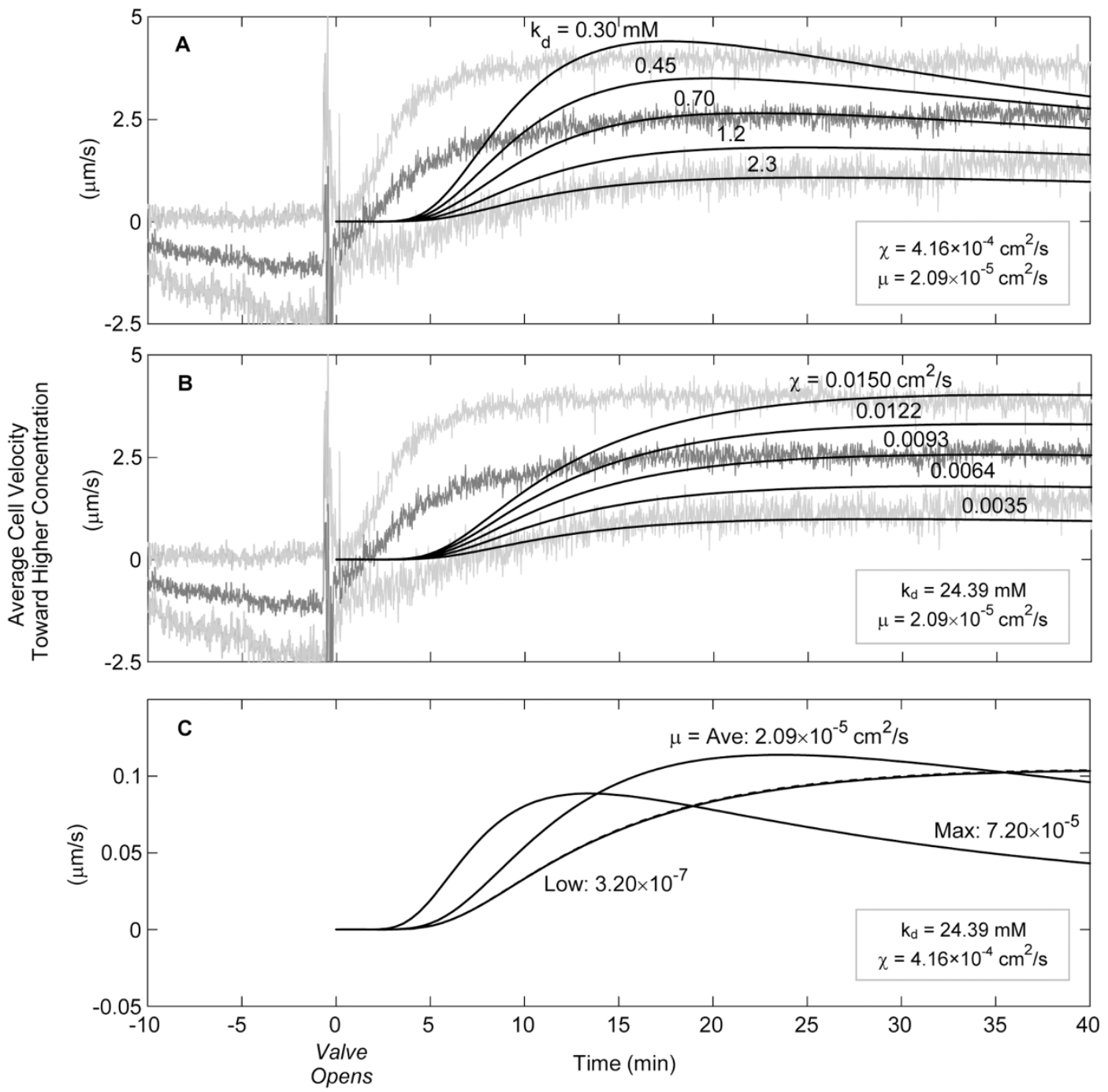

Figure $4 \mid$ Model fitting results (smooth black lines) overlaid on experimental results with $95 \%$ confidence intervals (grey lines) (A) using average literature values for $\chi$ and $\mu$ and varying $k_{d}$ over the range shown or (B) using average literature values for $k_{d}$ and $\mu$ while varying $\chi$ over the range shown (C) or $\mu$ varied across the range of literature values.

chemotaxis-induced convective flow is difficult to demonstrate conclusively, increased mass transport in the capillary could affect mass transport predictions.

A diffusion coefficient correction term, $\delta$, was introduced as a tool to investigate the effect of increased mass transport on the predicted response time. The correction was applied to the $\mathrm{H}_{2}$ diffusion coefficient and the random cell diffusion coefficient $(\mu)$ simultaneously, making the assumption that micro-scale convection was the primary source of error. Any convection would affect the random diffusion of cells and the diffusion of $\mathrm{H}_{2}$ equally. Increased mass transport in the liquid (simulating convection) caused an earlier response in all conditions that were investigated (see Supplementary Fig. S4 online). The value of $\delta$ is likely to be on the order of $1 \times 10^{-9}$ to $1 \times$ $10^{-8} \mathrm{~cm}^{2} \mathrm{~s}^{-1}$ based on curve shape and response time as compared to the experimental velocity data.

Another possible explanation for the more rapid experimental response is the presence of more than one type of $\mathrm{H}_{2}$ receptor with varying affinities. This would allow $M$. maripaludis to respond to $\mathrm{H}_{2}$ across a wider range of concentrations. The predicted $k_{d}$ value $0.7 \mathrm{mM}$ is high, and the presence of a high affinity receptor in $M$. maripaludis is likely. B. subtilis $\mathrm{O}_{2}$ receptors with two distinct affinities and binding components have been shown ${ }^{30}$. The presented data demonstrate a chemotactic response to $\mathrm{H}_{2}$, but more focused physiological studies and subsequent model refinement are needed to better represent this poorly understood phenomenon.

In our capillary assay, cells were not observed to accumulate in bands despite the chemotactic response observed. Typical chemotactic bands observed in capillary and swarm plate assays result from cell accumulation as a net result of a biased random walk ${ }^{16}$. In the capillary assay used, convection inside the capillary may have prevented cell accumulation. It is also possible that there are factors involved in chemotactic band formation that are unique between organisms or factors specific to hydrogenotaxis (e.g., swimming mode, adaption response, quorum sensing).

In our work, banding-like behavior was observed on a larger scale when $M$. maripaludis batch cultures were grown statically with $\mathrm{H}_{2}$. Under these conditions a pellicle formed at the gas-liquid interface (Figure 5A, B). This is a similar observation to the one made by Beijernck in 1893, where aerotactic cells were observed swimming toward the meniscus of a test tube ${ }^{16}$. When cultures of M. maripaludis were grown statically with the soluble electron donor formate, cells grew throughout the liquid medium (not in a pellicle) and had less cell-associated carbohydrate than $\mathrm{H}_{2}$-grown pellicle cultures (see Supplementary Fig. S5 online). These results suggest that 

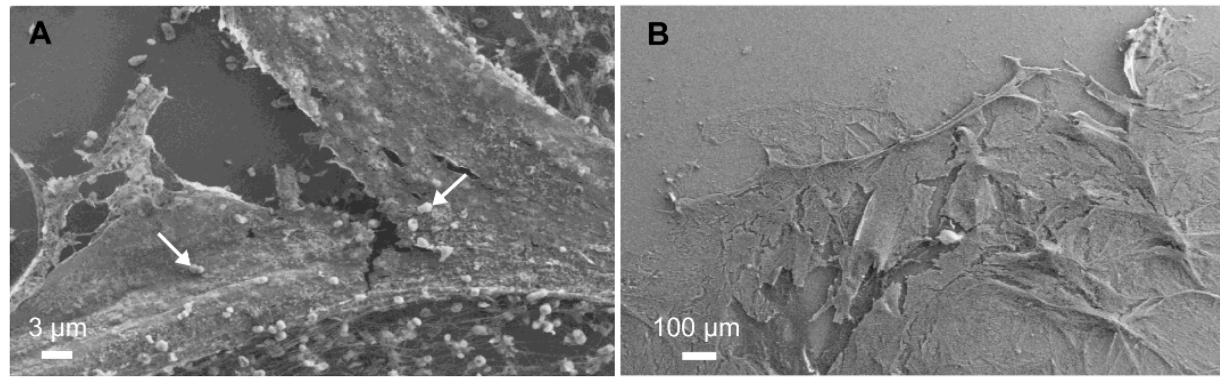

Figure $5 \mid$ (A) and (B) Field emission scanning electron micrographs of $M$. maripaludis pellicle with extracellular material and cells (indicated by arrows in (A)).

extra-polymeric substance (EPS) production is important for the formation of a pellicle in response to a $\mathrm{H}_{2}$ gradient and may require a time-scale longer than used in the capillary experiment.

\section{Discussion}

The hydrogenotrophic methanogen, M. maripaludis, displays chemotactic behavior toward $\mathrm{H}_{2}$ gas (hydrogenotaxis). Changes in $\mathrm{pH}$ were not observed in medium with or without $\mathrm{H}_{2}$ under the tested growth conditions and times, and these results indicate that the observed taxis was in response to $\mathrm{H}_{2}$ and not $\mathrm{H}^{+}$. Although the commonly used Keller-Segel model was not able to predict the exact response with previously published parameter ranges (values), parameter adjustment allowed the model to replicate the trend on a scale similar to other organisms and chemoattractants. The ability to move toward higher concentrations of $\mathrm{H}_{2}$ could incur an advantage to methanogens that are otherwise outcompeted by those that are able to use $\mathrm{H}_{2}$ at lower concentrations and/or utilize terminal electron acceptors that are more energetically favorable. The demonstrated chemotactic response would also allow cells to maintain desirable localization with respect to the major energy source as well as allow for proximity to $\mathrm{H}_{2}$-producers in mixed communities. Thus, hydrogenotaxis could play a crucial role in the establishment and maintenance of microbial interactions at the population- and community-level. The observed hydrogenotaxis could represent a widespread eco-physiological strategy of methanogens and other hydrogen-utilizing microbes that are important to processes such as bioremediation and overall carbon cycling ${ }^{4,33} \cdot \mathrm{CH}_{4}$ is a potent greenhouse gas that has an estimated global warming potential (GWP) 25-40\% higher than $\mathrm{CO}_{2}$ per molecule ${ }^{34}$. The three largest contributions of $\mathrm{CH}_{4}$ to atmospheric flux as of 2010 (wetlands, ruminant emissions, and rice cultivation) are the net result of the activity of anaerobic communities dominated by the exchange of $\mathrm{H}_{2}{ }^{35,36}$. To the best of our knowledge this is the first direct observation of hydrogenotaxis in any domain of life.

\section{Methods}

Culturing conditions. Methanococcus maripaludis strain S2 was grown in Balch tubes or serum bottles fitted with black butyl stoppers (Geo-Microbial Technologies Inc., Ochelata, OK) and aluminum crimp seals. Methanococcus Culture Medium (MCC) was prepared under a stream of anoxic $80 \% \mathrm{~N}_{2}, 20 \% \mathrm{CO}_{2}$ and contains per liter $0.33 \mathrm{~g} \mathrm{KCl}, 2.7 \mathrm{~g}, \mathrm{MgCl}_{2} \bullet 6 \mathrm{H}_{2} \mathrm{O}, 3.5 \mathrm{~g} \mathrm{MgSO}_{4} \bullet 7 \mathrm{H}_{2} \mathrm{O}, 0.14 \mathrm{~g} \mathrm{CaCl}_{2} \bullet 2 \mathrm{H}_{2} \mathrm{O}, 0.5 \mathrm{~g}$ $\mathrm{NH}_{4} \mathrm{Cl}, 5 \mathrm{~g} \mathrm{NaHCO}_{3}, 22 \mathrm{~g} \mathrm{NaCl}, 0.14 \mathrm{~g} \mathrm{~K}_{2} \mathrm{HPO}_{4}, 5 \mathrm{~mL} \mathrm{FeSO}_{4}$ solution $(0.19 \mathrm{~g}$ $\mathrm{FeSO}_{4} \cdot 7 \mathrm{H}_{2} \mathrm{O} / 100 \mathrm{~mL}$ of $10 \mathrm{mM} \mathrm{HCl}$ ), $1 \mathrm{~mL}$ trace metal solution (per $100 \mathrm{~mL} ; 2.1 \mathrm{~g}$ $\mathrm{Na}_{3}$ Citrate $\bullet 2 \mathrm{H}_{2} \mathrm{O}$, adjust $\mathrm{pH}$ to 6.5 , then $0.45 \mathrm{~g} \mathrm{MnSO}_{4} \bullet \mathrm{H}_{2} \mathrm{O}, 0.1 \mathrm{~g} \mathrm{CoCl}_{2} \bullet 6 \mathrm{H}_{2} \mathrm{O}$, $0.1 \mathrm{~g} \mathrm{ZnSO}_{4} \bullet 7 \mathrm{H}_{2} \mathrm{O}, 0.01 \mathrm{~g} \mathrm{CuSO}_{4} \bullet 5 \mathrm{H}_{2} \mathrm{O}, 0.01 \mathrm{~g} \mathrm{AlK}\left(\mathrm{SO}_{4}\right)_{2}, 0.01 \mathrm{~g} \mathrm{H}_{3} \mathrm{BO}_{4}, 0.1 \mathrm{~g}$ $\mathrm{Na}_{2} \mathrm{MoO}_{4} \bullet 2 \mathrm{H}_{2} \mathrm{O}, 0.025 \mathrm{~g} \mathrm{NiCl}_{2} \bullet 6 \mathrm{H}_{2} \mathrm{O}, 0.2 \mathrm{~g} \mathrm{Na}_{2} \mathrm{SeO}_{3}, 0.01 \mathrm{~g} \mathrm{VCl}_{3}, 0.0033 \mathrm{~g}$ $\mathrm{Na}_{2} \mathrm{WO}_{4} \cdot 2 \mathrm{H}_{2} \mathrm{O}$ ) $10 \mathrm{~mL}$ of vitamin solution (per liter; $2 \mathrm{mg}$ biotin, $2 \mathrm{mg}$ folic acid, $10 \mathrm{mg}$ pyridoxine $\mathrm{HCl}, 5 \mathrm{mg}$ thiamine $\mathrm{HCl}, 5 \mathrm{mg}$ riboflavin, $5 \mathrm{mg}$ nicotinic acid, $5 \mathrm{mg}$ DL-calcium pantothenate, $0.1 \mathrm{mg}$ vitamin B12, $5 \mathrm{mg} \rho$-aminobenzoinc acid, $5 \mathrm{mg}$ lipoic acid), $1 \mathrm{~mL}$ of Resazurin solution $(1 \mathrm{~g} / \mathrm{L})$. This solution is boiled under a stream of gas before adding $0.5 \mathrm{~g}$ cysteine $\bullet \mathrm{H}_{2} \mathrm{O} \bullet \mathrm{HCl}$, then cooled under gas ${ }^{37}$. The solution was dispensed anaerobically and autoclaved. After inoculation, the headspace was displaced and pressurized to 25 PSI with anoxic $80 \% \mathrm{H}_{2}: 20 \% \mathrm{CO}_{2}$ through a sterile filter. Modified MCC medium was used for growth experiments with formate, where $\mathrm{NaCl}$ was reduced to $10.5 \mathrm{~g} / \mathrm{L} ; 200 \mathrm{mM} \mathrm{Na}$-formate and $200 \mathrm{mM} 3$ (N-morpholino) propanesulfonic acid (MOPS) were added, and no $\mathrm{H}_{2}$ was added.

Cultures for taxis experiments were grown at $30^{\circ} \mathrm{C}$ (with no shaking) from frozen glycerol stocks in $40 \mathrm{~mL} \mathrm{MCC} \mathrm{in} 125 \mathrm{~mL}$ serum bottles to late exponential phase, then transferred to $5 \mathrm{~mL}$ MCC ( $10 \%$ inoculum) in $18 \times 150 \mathrm{~mm}$ Balch tubes. These working cultures were grown to stationary phase (around $120 \mathrm{~h}$ and average cell density 69,420 cells $/ \mathrm{mL}$ ). $1 \mathrm{~mL}$ of culture was added to $5 \mathrm{~mL}$ fresh MCC in a Balch tube with no $\mathrm{H}_{2}$ and either incubated for $4-5 \mathrm{~h}$ at $30^{\circ} \mathrm{C}$ under starvation conditions (no electron source), or used immediately for non-starvation conditions. Media salts were separated from cell suspension prior to taxis experiments by centrifuging the inverted Balch tube $\left(100 \times \mathrm{g} ; 30^{\circ} \mathrm{C}\right.$ for 10 minutes $)$.

Electron microscopy. Pellicles were removed from tubes with a plastic inoculating loop and placed on a round coverslip freshly treated with poly-L-Lysine $(1 \mu \mathrm{g} / \mathrm{mL})$ and fixed in a solution of $2 \%$ paraformaldehyde, $2.5 \%$ glutaraldehyde and $0.05 \mathrm{M} \mathrm{Na}$ cacodylate overnight at room temperature. Coverslips were rinsed and stepwise dehydrated in ethanol, and then critical point dried on a Samdri-795 (tousimis, Rockville, MD). Coverslips were mounted on SEM stubs with double-sided carbon tape and colloidal silver, and then sputter coated with Iridium for $35 \mathrm{~s}$ at $35 \mathrm{~mA}$. Images were collected on a Zeiss Supra55VP FE-SEM.

Capillary assay. Square glass capillary tubes $(1.0 \mathrm{~mm})$ with the ends fitted with norprene tubing connected to a polypropylene female luer-lock hose barb adapter (Cole-Parmer, Vernon Hills, IL) were partially filled with the cell suspension in an anaerobic chamber that contained only $\mathrm{N}_{2}$ and $\mathrm{CO}_{2}$. A $5 \mathrm{~mL}$ glass gas-tight luer lock syringe (SGE, Inc., Austin, TX) was used to transfer the cells to the capillary, and left attached to the capillary with the valve closed. A second $5 \mathrm{~mL}$ glass gas-tight syringe with $100 \% \mathrm{H}_{2}$ was attached to the gas side of the capillary (see Supplementary Fig. S1 online). The entire syringe/capillary assembly was removed from the anaerobic chamber and placed in a petri dish water bath on the microscope stage and firmly secured with poster putty and tape (see Supplementary Fig. S3 online).

Microscopic observation of swimming behavior and image analysis. A Leica TCS SP5 II upright confocal microscope was enclosed in an incubation chamber and was equilibrated to $30^{\circ} \mathrm{C}$. High-resolution time lapse images were collected every $0.753 \mathrm{~s}$ at the center of the capillary, $0.5 \mathrm{~cm}$ from the cell suspension/gas phase interface. A 25 $X$ water-dipping objective was used and a $3 \times$ optical zoom was applied resulting in a final field of view of $206.9 \times 206.9 \mu \mathrm{m}^{2}$ and a pixel size of $0.20 \mu \mathrm{m}$. Images were initially acquired for 10 minutes with $\mathrm{N}_{2} / \mathrm{CO}_{2}$ in the gas phase, then the valve was opened to the $\mathrm{H}_{2}$ syringe and images were captured for 40 minutes. The control experiments were identical to the above except that $100 \%$ Ar was used instead of $\mathrm{H}_{2}$, and images were acquired for a minimum of 8 minutes before the valve was opened and 38 minutes after.

Images were manually thresholded and binarized using MetaMorph v. 7.6 (Molecular Devices, Sunnyvale, CA). Binary images were analyzed using Imaris v. 7.5.2 (Bitplane, Inc., South Windsor, CT) with a particle-tracking module (Imaris Track). $1 \mathrm{~s}, 5 \mathrm{~s}$, and $10 \mathrm{~s}$ filter durations were tested where a given track was only analyzed if it was as long or longer than the specified duration. The $5 \mathrm{~s}$ filter was used for the described analyses, and differences were not observed in overall trends between track lengths.

Chemotaxis model. A one dimensional finite element model was constructed using Comsol Multiphysics Version 4.3 a that solves Equations 2 and 4 simultaneously in the liquid domain. Diffusion of hydrogen through the gas domains was modeled by Maxwell-Stefan equations. All model parameters were corrected for temperature $\left(30^{\circ} \mathrm{C}\right)$ and salinity $(2.65 \% \mathrm{~m} / \mathrm{v})$ of the medium, where possible, and hydrogen consumption rate parameters were estimated from literature values. Supplementary Table S1 online shows all constants used in the model.

The geometry of the model consisted of one liquid domain and two gas domains separated by a valve that opens at $\mathrm{t}=0$ to start the diffusion of hydrogen into the system. The short segment between the valve and the far right boundary is the length of the connection between the valve and the main volume of the gas-tight syringe. The geometry for each experimental replicate was slightly different so average lengths were used. The diffusion of hydrogen through the gas domain of the capillary was 
expected to be much faster than diffusion through the liquid domain so the precise length of the gas domain was not expected to affect the analysis. The diffusionlimiting segment between the liquid-gas interface and the point of observation $0.5 \mathrm{~cm}$ into the liquid remained constant through all replicates and is therefore not an average value. Initial conditions are zero hydrogen inside the capillary, 100\% hydrogen behind the valve in the second gas domain and a constant population density in the liquid domain. Supplementary Figure S1 online shows the geometry, initial conditions and boundary conditions used in the model.

The model geometry was meshed at a maximum element size of $0.1 \mathrm{~mm}$ and time step discretization was done with a backward differentiation formula (BDF) method. The time steps taken by the solver were allowed to be free with larger steps being taken at later time points where gradients are shallower. A relative solution tolerance of $10^{-20}$ was imposed and PARDISO ${ }^{38}$ was the general direct solver as implemented in Comsol.

Most parameters in the model are well known or able to be calculated from the literature with the exception of the chemotaxis constants $\chi, \mu$ and $\mathrm{k}_{\mathrm{d}}$. A literature search was performed for observed chemotaxis values in any organism to establish a range of reasonable values. Twelve applicable values were found for $\chi$, twenty-one for $\mu$ and seven for $\mathrm{k}_{\mathrm{d}}$. Maximum, average and minimum values for each are found in Table S1. The model was fitted to the average swimming velocity data by independently varying one chemotaxis parameter by trial and error while keeping the other two constant at the average literature value found in Supplementary Table S1 online.

Every effort was made to model the diffusion of hydrogen into the liquid domain accurately; however, the likelihood of unpredictable factors such as micro-scale mixing due to convection still exists. To provide the flexibility to correct for enhanced mass transport, a correction term was applied such that

$$
D_{\text {Haq }}^{\prime}=D_{H a q}+\delta
$$

Where $\delta$ represents the mass transport enhancement beyond what is predicted from Fickian diffusion alone and $\mathrm{D}_{\mathrm{Haq}}$ is the corrected diffusion coefficient used in the model for this analysis. Similarly, $\delta$ was also applied to the random cell diffusion coefficient such that

$$
\mu^{\prime}=\mu+\delta
$$

because any correction applied to $\mathrm{D}_{\mathrm{Haq}}$ would need to be applied to $\mu$ on grounds that convection would affect the movement of cells the same as the pass transport of $\mathrm{H}_{2}$.

Carbohydrate and protein measurements. Protein concentrations were determined with the Lowry assay using bovine serum albumin as the standard ${ }^{39}$. Hexose sugars were measured by the colorimetric cysteine-sulfuric acid method with glucose as the standard. Pentose sugars were measured with a colorimetric orcinol- $\mathrm{FeCl}_{3}$ assay with xylose as the standard. A colorimetric carbazole assay was used to measure uronic acid concentration with D-galacturonic acid as the standard ${ }^{40}$.

1. Ferrera, I. et al. Diversity of $16 \mathrm{~S}$ rRNA gene, ITS region and $a c l B$ gene of the Aquificales. Extremophiles 11, 57-64 (2006).

2. Reysenbach, A. L., Longnecker, K. \& Kirshtein, J. Novel Bacterial and Archaea Lineages from an In Situ Growth Chamber Deployed at a Mid-Atlantic Ridge Hydrothermal Vent. Applied and Environmental Microbiology 66, 3798-3806 (2000)

3. Poehlein, A. et al. An Ancient Pathway Combining Carbon Dioxide Fixation with the Generation and Utilization of a Sodium Ion Gradient for ATP Synthesis. PLoS ONE 7, 1-8 (2012)

4. Petersen, J. M. et al. Hydrogen is an energy source for hydrothermal vent symbioses. Nature 476, 176-180 (2012).

5. Thauer, R. K. The Wolfe cycle comes full circle. Proc. Natl. Acad. Sci. U.S.A. 109, 15084-15085 (2012).

6. Ueno, Y., Yamada, K., Yoshida, N., Maruyama, S. \& Isozaki, Y. Evidence from fluid inclusions for microbial methanogenesis in the early Archaean era. Nature 440, 516-519 (2006).

7. Jarrell, K. F. et al. Major players on the microbial stage: why archaea are important. Microbiology 157, 919-936 (2011).

8. Conway de Macario, E. \& Macario, A. J. L. Methanogenic archaea in health and disease: A novel paradigm of microbial pathogenesis. Int. J. Med. Microbiol. 299, 99-108 (2009)

9. Herzog, B. \& Wirth, R. Swimming Behavior of Selected Species of Archaea. Applied and Environmental Microbiology 78, 1670-1674 (2012).

10. Migas, J., Anderson, K. L., Cruden, D. L. \& Markovetz, A. J. Chemotaxis in Methanospirillum hungatei. Applied and Environmental Microbiology 55, 264-265 (1989).

11. Sment, K. A. \& Konisky, J. Chemotaxis in the archaebacterium Methanococcus voltae. Journal of Bacteriology 171, 2870-2872 (1989).

12. Schlesner, M. et al. Identification of Archaea-specific chemotaxis proteins which interact with the flagellar apparatus. BMC Microbiol 9, 56-56 (2009).

13. Lacal, J., García-Fontana, C., Muñoz-Martínez, F., Ramos, J.-L. \& Krell, T. Sensing of environmental signals: classification of chemoreceptors according to the size of their ligand binding regions. Environ Microbiol 12, 2873-2884 (2010).

14. Thomas, N. A. \& Jarrell, K. F. Characterization of Flagellum Gene Families of Methanogenic Archaea and Localization of Novel Flagellum Accessory Proteins. Journal of Bacteriology 183, 7154-7164 (2001).
15. Porter, S. L., Wadhams, G. H. \& Armitage, J. P. Signal processing in complex chemotaxis pathways. Nat Rev Micro 9, 153-165 (2011).

16. Adler, J. Chemotaxis in Bacteria. Science 153, 708-716 (1966).

17. Keller, E. F. \& Segel, L. A. Model for chemotaxis. Journal of Theoretical Biology 30, 225-234 (1971)

18. Lapidus, I. R. \& Schiller, R. Model for the chemotactic response of a bacterial population. Biophysj 16, 779-789 (1976).

19. Tindall, M. J., Maini, P. K., Porter, S. L. \& Armitage, J. P. Overview of Mathematical Approaches Used to Model Bacterial Chemotaxis II: Bacterial Populations. Bull. Math. Biol. 70, 1570-1607 (2008).

20. Streif, S., Staudinger, W. F., Marwan, W. \& Oesterhelt, D. Flagellar Rotation in the Archaeon Halobacterium salinarum Depends on ATP. Journal of Molecular Biology 384, 1-8 (2008).

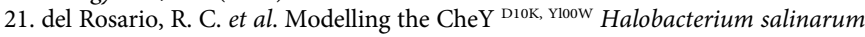
mutant: sensitivity analysis allows choice of parameter to be modified in the phototaxis model. IET systems biology 1, 207-221 (2007).

22. Alatyrev, A. G. et al. Identification of the New Protein Participitating in the Archaea Motility Regulation. Biol Membrany 27, 121-132 (2010).

23. Adler, J. \& Dahl, M. M. A Method for Measuring the Motility of Bacteria and for Comparing Random and Non-random Motility. J Gen Microbiol 46, 161-173 (1967).

24. Thauer, R. K., Kaster, A.-K., Seedorf, H., Buckel, W. \& Hedderich, R. Methanogenic archaea: ecologically relevant differences in energy conservation. Nat Rev Micro 6, 579-591 (2008).

25. Lovley, D. R. Minimum threshold for hydrogen metabolism in methanogenic bacteria. Applied and Environmental Microbiology 49, 1530-1531 (1985).

26. Kaster, A.-K., Moll, J., Parey, K. \& Thauer, R. K. Coupling of ferredoxin and heterodisulfide reduction via electron bifurcation in hydrogenotrophic methanogenic archaea. Proc. Natl. Acad. Sci. U.S.A. 108, 2981-2986 (2011).

27. Ver Eecke, H. C. et al. Hydrogen-limited growth of hyperthermophilic methanogens at deep-sea hydrothermal vents. Proc. Natl. Acad. Sci. U.S.A. 109, 13674-13679 (2012).

28. Armitage, J. P. \& Schmitt, R. Bacterial chemotaxis: Rhodobacter sphaeroides and Sinorhizobium meliloti-variations on a theme? Microbiology 143, 3671-3682 (1997).

29. Ahmed, T. \& Stocker, R. Experimental Verification of the Behavioral Foundation of Bacterial Transport Parameters Using Microfluidics. Biophysical Journal 95, 4481-4493 (2008).

30. Zhang, W., Olson, J. S. \& Phillips Jr, G. N. Biophysical and Kinetic Characterization of HemAT, an Aerotaxis Receptor from Bacillus subtilis. Biophysj 88, 2801-2814 (2005).

31. Lewus, P. \& Ford, R. M. Quantification of Random Motility and Chemotaxis Bacterial Transport Coefficients Using Individual-Cell and Population-Scale Assays. Biotechnol. Bioeng. 75, 292-304 (2001).

32. Kim, M. \& Kim, T. Diffusion-Based and Long-Range Concentration Gradients of Multiple Chemicals for Bacterial Chemotaxis Assays. Anal. Chem. 82, 9401-9409 (2010).

33. Kleiner, M. et al. Metaproteomics of a gutless marine worm and its symbiotic microbial community reveal unusual pathways for carbon and energy use. Proc. Natl. Acad. Sci. U.S.A. 109, E1173-E1182 (2012).

34. Shindell, D. T. et al. Improved Attribution of Climate Forcing to Emissions. Science 326, 716-718 (2009).

35. Neef, L., van Weele, M. \& van Velthoven, P. Optimal estimation of the present-day global methane budget. Global Biogeochem. Cycles 24, 1-10 (2010).

36. Schlesinger, W. H. \& Bernhardt, E. S. Biogeochemistry: An Analysis of Global Change. $3^{\text {rd }}$ Ed. (Academic Press, Waltham, MA, 2013).

37. Miller, T. L. \& Wolin, M. J. A Serum Bottle Modification of the Hungate Technique for Cultivating Obligate Anaerobes. Appl Microbiol 27, 985-987 (1974).

38. Schenk, O. \& Gärtner, K. Solving unsymmetric sparse systems of linear equations with PARDISO. Future Gener Comput Syst 20, 475-487 (2004).

39. Lowry, O. H., Rosebrough, N. J., Farr, A. L. \& Randall, R. J. Protein Measurement with the Folin Phenol Reagent. J biol chem 193, 265-275 (1951).

40. Chaplin, M. F. \& Kennedy, J. F. Carbohydrate Analysis: A Practical Approach. The Practical Approach Series. $2^{\text {nd }}$ Ed. (Irl Press, Oxford, 1994).

\section{Acknowledgments}

The authors wish to thank Sara Altenburg for helping with the $\mathrm{pH}$ experiment, Betsey Pitts for microscopy assistance, Gill Geesey for encouraging us to pursue the experiments, $\mathrm{Al}$ Parker for assistance with statistics, Adam Arkin and Roland Hatzenpichler for helpful comments, and William B. Whitman for his suggestion to use formate. This work conducted by ENIGMA- Ecosystems and Networks Integrated with Genes and Molecular Assemblies (http://enigma.lbl.gov), a Scientific Focus Area Program at Lawrence Berkeley National Laboratory, was supported by the Office of Science, Office of Biological and Environmental Research, of the U. S. Department of Energy under Contract No. DE-AC02-05CH11231. K.A.B. and J.M.C. were also supported by a NSF-IGERT fellowship in Geobiological Systems at Montana State University (DGE 0654336). Partial support for R.G. was provided through the National Science Foundation under CHE-1230632. The confocal microscopy equipment used was purchased with funding from the NSF-Major Research Instrumentation Program and the M.J. Murdock Charitable Trust. 


\section{Author contributions}

K.A.B. developed experimental design, performed experiments, critically evaluated the model, wrote and revised the manuscript. J.M.C. developed experimental design, performed experiments, created the model, wrote and revised the manuscript. C.D. performed experiments and revised the manuscript. R.G. developed experimental design, critically evaluated the model, and revised the manuscript. M.W.F. developed experimental design, critically evaluated the model, and revised the manuscript.

\section{Additional information}

Supplementary information accompanies this paper at http://www.nature.com/ scientificreports
Competing financial interests: The authors declare no competing financial interests. How to cite this article: Brileya, K.A., Connolly, J.M., Downey, C., Gerlach, R. \& Fields, M.W. Taxis Toward Hydrogen Gas by Methanococcus maripaludis. Sci. Rep. 3, 3140; DOI:10.1038/srep03140 (2013).

(c) (1) (2) (2) This work is licensed under a Creative Commons AttributionBy NC SA NonCommercial-ShareAlike 3.0 Unported license. To view a copy of this license, visit http://creativecommons.org/licenses/by-nc-sa/3.0 
SUBJECT AREAS:

ENVIRONMENTAL MICROBIOLOGY

ARCHAEA BIOLOGY

SCIENTIFIC REPORTS:

$3: 3140$

DOI: $10.1038 /$ srep03140

(2013)

Published:

5 November 2013

Updated:

23 January 2014
CORRIGENDUM: Taxis Toward Hydrogen Gas by Methanococcus maripaludis

Kristen A. Brileya, James M. Connolly, Carey Downey, Robin Gerlach \& Matthew W. Fields

The Supplementary Movies that accompany this study were omitted from the original version of this Article. 